\title{
O PLANEJAMENTO TERRITORIAL NA FRANÇA E NO BRASIL: UMA ABORDAGEM COMPARATIVA
}

\author{
TERRITORIAL PLANNING IN FRANCE AND BRAZIL: A COMPARATIVE APPROACH ABSTRACT
}

\section{RESUMO}

O artigo realiza uma comparação entre as abordagens territoriais das políticas públicas no Brasil e na França, até a década de 80 e desta data aos dias atuais, com destaque para a Política Nacional de Desenvolvimento Regional (PNDR) brasileira e os Contratos de Plano Estado-região (CPER) franceses. Embora esses dois países possuam formações político-econômicas diferentes, a centralidade que o tema ocupa na agenda estatal francesa e a abordagem intersetorial, contrastam com a marginalidade das políticas desenvolvida pelo governo brasileiro. $O$ texto parte da hipótese de que, no Brasil, a construção de políticas territoriais com foco na redução das desigualdades regionais, enfrentou, em sua história recente, dificuldades pela ausência de um projeto nacional de desenvolvimento estruturado, agravado pelo processo de fragmentação clientelística presentes na estruturação do Estado brasileiro.

Palavras-chave: planejamento territorial, contratos de plano, políticas de desenvolvimento regional, políticas públicas.

\section{ABSTRACT}

The article makes a comparison between the territorial approaches of the public policies in Brazil and in France, until the 80's and from this date to the present day, with emphasis on the Brazilian National Development Policy (PNDR) and the Stateregion plan contract (CPER). Although these two countries have different political and economic formations, the centrality that the theme occupies in the French state agenda and the intersectoral approach contrasts with the marginality of the policies developed by the Brazilian government. The text is based on the hypothesis that, in Brazil, the construction of territorial policies focused on the reduction of regional inequalities has, in its recent history, faced difficulties due to the absence of a national project of a structured development, aggravated by the process of clientelistic fragmentation present in the structure of the Brazilian State.

Keywords: territorial planning, plan contracts, regional development policies, public policy.

\author{
Antonio Paulo Cargnin a, b \\ D Bruno de Oliveira Lemos ${ }^{b}$ \\ (D) Aldomar Arnaldo Rückert ${ }^{\text {b }}$ \\ ${ }^{\text {a }}$ Secretaria do Planejamento, \\ Orçamento e Gestão (SEPLAG/RS), Porto \\ Alegre, RJ, Brasil \\ ${ }^{\text {b }}$ Universidade Federal do Rio Grande do \\ Sul (UFRGS), Porto Alegre, RJ, Brasil
}

DOI: $10.12957 /$ geouerj.2020.43601

Correpondência: apcargnin@gmail.com

Recebido em: 28 jun. 2019

Aceito em: 19 abr.2020

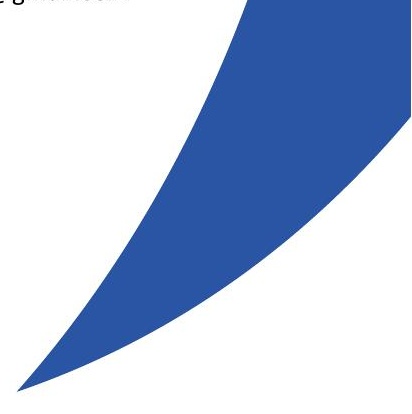




\section{INTRODUÇÃO}

O presente artigo tem como objetivo realizar uma comparação entre as abordagens territoriais das políticas públicas no Brasil e na França. Essa perspectiva é de grande relevância pois adiciona um componente de análise que possibilita uma maior transversalidade das diferentes ações estatais, estabelecendo coerência no sentido de se enfrentar as desigualdades regionais ${ }^{1}$.

Os dois países possuem características distintas nos seus territórios, refletindo a peculiaridade de sua história e de sua geografia. Sem a pretensão de recontar a evolução do planejamento territorial, recupera-se alguns aspectos dos seus processos de formação, considerados fundamentais para entender as diferenças existentes na abordagem e no sucesso das políticas territoriais nos dois países.

Ao se referir à formação da França após a Revolução Francesa, Subra (2016, p.183), afirma que essa se traduziu em uma acentuação do caráter centralizado do Estado, defendida pela corrente mais radical jacobina que considerava essa característica como fundamental para a defesa da Revolução contra inimigos externos e internos, ao contrário dos Girondinos, que se qualificavam como federalistas. Esse modelo se reproduziu durante quase toda a história francesa, até a década de 1980, quando a crise do Estado francês gera um processo de descentralização política.

A formação política e territorial do Brasil já foi objeto de estudo de diversos autores, não cabendo abordar neste artigo seus inúmeros debates. Furtado (2013, p.378), como exemplo, afirma que as diferenças entre os federalismos europeu e brasileiro residem na busca de formas de convivência de um grupo de nacionalidades ligadas por vínculos históricos no quadro de uma mesma organização estatal no primeiro caso, enquanto no Brasil a luta pelo federalismo está ligada às aspirações de desenvolvimento das diferentes áreas de seu imenso território, como na descentralização da Primeira República, na qual a política do governo central foi subjugada aos interesses da região em mais rápida expansão.

Algumas tentativas de integrar esse território se deram durante o período Vargas e na ideia de segurança nacional da ditadura militar. Embora tenham sido implementadas por meio de grandes projetos de investimento, Vainer (2007, p.11) observa que estes contribuíram ainda mais para a fragmentação territorial verificada até os dias atuais.

Dessa forma, as relações entre políticas setoriais e territoriais no Brasil e na França se apresentam de forma diferente. Enquanto na França a descentralização política dos anos 1980 gerou uma dificuldade de articulação entre as políticas nacionais e regionais, para a qual foram criados os contratos de plano Estado-

\footnotetext{
${ }^{1} \mathrm{O}$ artigo resulta de um intercâmbio realizado entre pesquisadores da Secretaria do Planejamento, Governança e Gestão do Estado do Rio Grande do Sul e da Universidade Federal do Rio Grande do Sul, no Brasil, e do Comissariat Général à l'Égalité des Territoires (CGET), na França, tendo sido realizado em setembro de 2018, com objetivo de estabelecer possibilidades de cooperação técnica sobre instrumentos de planejamento territorial utilizados pelos dois países.
} 
região, no Brasil, essa dificuldade se dá historicamente devido à fragmentação do território nacional e aos diferentes interesses regionais presentes no Estado. Para Vainer (2007, p.15), as redes de patronagem/clientela presentes no Estado brasileiro estabelecem formas de defesa e negociação de interesses segmentados totalmente estranhos e alheios a políticas e projetos nacionais. Essa característica se reflete nas dificuldades de articulação entre as diferentes políticas ministeriais.

Este artigo, além de realizar um breve histórico das políticas territoriais dos dois países, aborda suas diferenças, consubstanciadas nos Contratos de Plano Estado-região franceses e na Política Nacional de Desenvolvimento Regional (PNDR) no Brasil. A hipótese é de que a construção de políticas territoriais com foco nas regiões de menor desenvolvimento se encontra dificultada por interesses segmentados, resultantes do processo de fragmentação clientelística do Estado brasileiro. Esse processo se reflete na marginalidade desse tipo de política no Brasil.

\section{A afirmação do planejamento territorial}

A origens mais evidentes de uma preocupação com o planejamento territorial são atribuídas às providências adotadas no plano de reação norte-americano à crise iniciada em 1929. Entre a série de políticas norte-americanas denominadas New Deal, promovidas pelo governo Roosevelt, a Tennessee Valley Authority (TVA), de 1933, implementou fortes ações na área de infraestrutura e de geração de empregos no sul dos Estados Unidos, resultando nos primeiros sinais de reação à grande depressão (BENKO, 1999, p.6).

Na Europa, as primeiras ações, ainda que pouco sistemáticas, de planejamento territorial podem ser observadas, ainda em um período anterior ao pós-guerra, como no caso da Grã-Bretanha e dos Países Baixos (BENKO, 1999, p. 6-7). Entretanto, a preocupação com o a integração e a coesão territorial e o equilíbrio territorial não foram um elemento central da estruturação do mercado comum europeu, tendo sido incorporada à agenda em um segundo momento (FALUDI, 2018, p.377-378).

Mesmo que apresente diversas denominações que denotam diferenças de abordagem, pode-se dizer que o planejamento do território, como ação sistemática dos Estados ocidentais, se inicia nos pós-Segunda Guerra Mundial como complemento dos planos de crescimento econômico surgidos no período. Para um maior entendimento de sua estruturação, faz-se importante compreender o cenário político-econômico surgido do conflito e o planejamento territorial como parte do welfare state então vigente. Segundo Gilpin (2002, p.152-153), as democracias ocidentais fixaram duas prioridades para o pós-guerra. A primeira era o crescimento econômico com pleno emprego, com o intervencionismo na economia e a instituição de um welfare state; e, a segunda, a criação de uma ordem econômica estável que impedisse o retorno do nacionalismo destrutivo dos anos 1930. 
Para esse segundo objetivo, foi criado, em 1944, o sistema monetário de Bretton Woods. Esse sistema se baseava em uma taxa de câmbio fixa entre o dólar e as principais moedas da Europa Ocidental e o Japão, em um modelo semelhante ao padrão ouro vigente entre o fim do século XIX e início do século XX. No entanto, sua principal diferença em relação a esse padrão, que entrou em crise em 1929, residia na gestão da produção do dinheiro mundial por uma série de organizações governamentais - como o Fundo Monetário Internacional (FMI) e o Banco Mundial, na teoria, e o Sistema da Reserva Federal dos Estados Unidos, na prática - e não por um grupo de banqueiros e financistas privados (ARRIGHI, 2009, p.287). Esse sistema conciliava estabilidade internacional, proporcionada pelas taxas de câmbio fixas, e autonomia nacional, com as políticas de pleno emprego oriundas do keynesianismo (GILPIN, 2002, p.152-153).

A instituição do sistema de Bretton Woods deu início a uma era de expansão do capitalismo sem precedentes entre as democracias ocidentais. Os investimentos norte-americanos, através do Plano Marshall, contribuíram para isso. No entanto, esse crescimento beneficiou as regiões centrais desses países, gerando desigualdades territoriais importantes.

Como resposta, de acordo com Desjardins (2017, p.18), quase todos os países da Europa Ocidental adotaram políticas de planejamento do território segundo as modalidades seguintes:

- Implantação de uma ou várias estruturas encarregadas não só de elaborar essas políticas, mas também de incitar os setores da administração pública a se organizarem de maneira compatível com essas;

- Criação de um conjunto de dispositivos administrativos para controlar o desenvolvimento;

- Fundos e ajudas específicas para investimentos públicos e privados em certas partes do território.

O importante papel do Estado na economia sofreu um choque com a crise do modelo de Bretton Woods no início da década de 1970. Para isso, contribuiu o aumento da inflação mundial, resultante da criação excessiva de dinheiro por parte dos Estados Unidos, e o aumento substancial dos déficits do governo federal deste país, o que impulsionava sua inflação e gerava perdas de competitividade da indústria nacional (KENNEDY, 1989, p.434). Esse processo gerou uma reação do governo norte-americano, principal líder desse sistema, com o fim da conversibilidade do dólar em ouro, sobretaxa às importações dos Estados Unidos e controle de salários e preços para combater a inflação no país, gerando uma desvalorização substancial do dólar em 1971 (GILPIN, 2002, p.162). Isso significou o abandono do papel de liderança monetária dos Estados Unidos, gerando uma expansão financeira em nível mundial e a diminuição da margem de ação dos Estados na economia. 


\section{O planejamento territorial na França}

A França é considerada um país pioneiro em instituir políticas voltadas ao equilíbrio territorial. Além da onda de intervencionismo econômico das democracias ocidentais, resultante da crise do liberalismo nos anos 1930 e das políticas de guerra do período 1939-1945, na França, ocorre um clima de desconfiança em relação ao capitalismo privado em razão de uma boa parte das elites econômicas ser suspeita de colaboração com a ocupação alemã e de enriquecimento ilícito entre 1940 e 1944, resultando em uma espécie de capitalismo sem capitalistas no pós-guerra (PIKETTY, 2013, p.218-220). Esse processo resultou em uma intervenção maior do Estado na economia francesa em relação a outras democracias, contando também com grande participação estatal nas maiores empresas do país.

As políticas de planejamento territorial na França até os anos 1980

As origens do que ficou conhecido como l'aménagement du territoire podem ser encontradas no trabalho do geógrafo Jean-François Gravier, Paris et le désert français, de 1947, que apontava para a concentração econômica excessiva em torno da capital francesa (SANTAMARIA, 2018). Os programas de planejamento regional da década de 1950 e a própria Délégation interministérielle à l'aménagement du territoire (DATAR), criada em 1963, também apresentavam um caráter fortemente economicista².

Girardon (2010, p.38), analisando o caso francês, afirma que, até a metade dos anos 1980, o planejamento territorial se caracterizava pela forte presença estatal, sendo desenvolvido de forma centralizada. Com a descentralização política promovida pelo governo Mitterand nos 1980, as regiões passaram a propor suas orientações e estratégias de desenvolvimento (MONOT, 2018, p.33). A partir de então, foram criados os instrumentos denominados contrats de plan État-region, com objetivo de articular o planejamento nacional com os das regiões (GIRARDON, 2010, p.144-145). Com isso, o conceito de planejamento do território deixa de ser unidimensional e ganha um sentido multiescalar, no que pode ser denominado de planejamento dos territórios (SANTAMARIA, 2018, p.445).

Em 1950, foi criada a Comission centrale d'études pour le plan d'aménagement national, seguida pela seção para Aménagement national e regional e o Fond national d'aménagement du territoire (FNAT). Os anos 1960, já no início de Quinta República, foram marcados pela criação do Comité interministériel pour les problèmes d'action regional et d'aménagement du territoire, em 1960, e, da mais conhecida, Délégation interministérielle à l'aménagement du territoire et l'action régionale (DATAR), em 1963 (SANTAMARIA, 2018, p.433).

\footnotetext{
2 Um apanhado sobre a situação do planejamento territorial dos países da União Europeia e vizinhos pode ser encontrado na obra coletiva coordenada por Dasí e Peiró (2018), Territorio y estados: elementos para la coordinación de las políticas de ordenación del territorio en el siglo XXI.
} 
Esse período, na França, foi marcado também por um Estado centralizado e planificador, o que se refletia nos quinquenais Plans de la Nation, visando ao crescimento da economia do país. Segundo Girardon (2010, p.35-36), foi apenas no segundo Plan de la Nation (1954-1957) que programas de ação regional começaram a tomar uma pequena dimensão territorial, com as primeiras medidas de desconcentração de atividades da indústria e de serviços em relação a Paris.

Essas ações de desconcentração se intensificaram, principalmente, com a política de metrópoles de equilíbrio, apoiada sobre as definições dos Plans de la Nation IV (1962-1965) e V (1965-1970). Essa política da DATAR escolheu oito cidades ${ }^{3}$ para receberem investimentos públicos substanciais nas áreas da habitação, desenvolvimento de equipamentos universitários e culturais, melhorias na infraestrutura viária e aeroportuária, criação de bairros voltados ao negócio (em Lyon, Bordeaux e Lille) e subsídios para empresas se estabelecerem. Os serviços públicos também foram descentralizados, com mais de 23.000 empregos desse setor gerados fora da região parisiense entre 1960 e 1990. Nos anos 1970, essa política foi estendida para setenta e três cidades médias entre 20.000 e 200.000 habitantes (GIRARDON, 2010, p.63-65).

Segundo Monot (2018, p.56), antes de 1975, o planejamento territorial francês adotava dois tipos de medidas no que se refere à desconcentração industrial: as dissuasivas eram marcadas pelas dificuldades para obter uma licença para construir e a necessidade de uma licença ministerial para se implantar na Île-de-France; as incitativas se referiam à gestão de estruturas, como viabilização de terrenos, melhorias nos transportes, incentivos fiscais e subsídios para a instalação em zonas a mais de 200 quilômetros de Paris e nas consideradas críticas pela DATAR, como a Córsega, o Maciço Central e a Bretanha. Os resultados dessas políticas são relativizados pela autora, que afirma que os cerca de 500 mil empregos gerados ocorreram em um raio de 200 a 250 quilômetros da capital francesa, sendo que os centros de decisão das empresas ainda estavam na capital. Desjardins (2017, p.65) afirma que essas políticas possibilitaram industrializar, principalmente, as regiões periféricas de Paris nos segmentos automotor e eletrônico.

Outro tipo de política territorial na França nesse período se referiu à conversão da economia de certas regiões industriais em crise, através da criação de novos tipos de empregos nas regiões mineiras e siderúrgicas do Nord-Pas-de-Calais, Lorraine e Maciço Central, principalmente no norte e no leste do país (MONOT, 2018, p.56). Nessa linha, foram implantadas estruturas de formação profissional para permitir aos trabalhadores se reciclarem e planos sociais foram implantados para liberar os empregados desses segmentos (GIRARDON, 2010, p.69). Também ocorreram ações de urbanismo para valorizar a imagem das cidades mineiras.

No entanto, nos anos 1980, além das críticas clássicas de liberais a esse modelo, somam-se críticas acadêmicas ao planejamento centralizado e tecnocrático. Esses fatores foram agravados pelo crescimento das

${ }^{3}$ Lyon, Marselha, Lille, Toulouse, Bordeaux, Estrasburgo, Nancy e Nantes. 
desigualdades territoriais na França (SANTAMARIA, 2018, p.441-442). Essas questões levaram a transformações no planejamento territorial francês.

As políticas de planejamento territorial na França após os anos 1980

Os anos 1980 foram marcados pela descentralização da estrutura estatal na França. Segundo Desjardins (2017, p.41), as leis de 1982 e 1983, que ganharam o nome do ministro do Interior Gaston Defferre, consistiam entre outros pontos, na transformação da unidade Região em uma coletividade territorial plena, administrada por um conselho regional eleito pela população, e a transferência de competências do Estado em direção às comunas, departamentos e regiões. Essas leis foram complementadas, recentemente, pelas de 2013 e 2014 , que reduziram o número dessas de 22 para 13 e atribuíram às regiões a elaboração de um schéma regional d'aménagement, de développement durable et d'égalité des territoires, que visa planejar as ações de longo prazo regionais. Com as regiões ganhando importância, o conceito de planejamento do território deixa de ser unidimensional e ganha um sentido multiescalar, no que pode ser denominado de planejamento dos territórios (SANTAMARIA, 2018, p.445).

Além da descentralização política, os anos 1980 foram marcados pela ascensão da globalização e pelo aumento do desemprego na França. Uma das políticas escolhidas para lidar com esse problema consistiu nos polos de conversão, criados em 1984, com foco em quinze regiões, propondo a criação de condições para sua renovação econômica. Em cada uma dessas regiões, os prefeitos procuraram mobilizar os atores locais para o desenvolvimento, foram promovidas incubadoras tecnológicas e estabelecidos planos sociais para a reconversão de assalariados para outros segmentos (GIRARDON, 2010, p.70-71). Dessa forma, a política dos anos anteriores, focada nas regiões mineiras e siderúrgicas, foi estendida para outras regiões. Os polos de conversão foram os precursores das zonas para a inovação e realizações científicas e técnicas (ZIRST) e dos tecnopolos.

Outra política que visava ao aumento da competitividade foi a dos sistemas produtivos locais, lançados pela DATAR em 1998, que objetivava o treinamento de mão-de-obra, promoção do marketing e melhorias nos processos de produção de pequenas e médias empresas localizadas em regiões específicas de segmentos escolhidos pela administração. Essa política ficou em segundo plano quando da criação dos polos de competitividade, em 2004, que visavam à cooperação, em um espaço geográfico dado, entre empresas, centros de formação e unidades de pesquisa públicos e privados, com o objetivo de gerar inovação. Em 2005, os sistemas e os polos foram classificados em 6 centros mundiais, 9 centros com vocação mundial e 52 outros centros. Os centros mundiais e com vocação mundial foram considerados de alta tecnologia, enquanto os outros centros se inseriram na lógica dos sistemas produtivos locais (MONOT, 2018, p.105-106). 
Santamaria (2018, p.448-449) afirma que, atualmente, as políticas territoriais francesas podem ser divididas em dois tipos:

- Sistemas de assistência a territórios em dificuldades econômicas, principalmente ajudas do setor público para a criação de empregos, as zonas de revitalização rural, e as diferentes formas de assistência financeira para negócios em certos territórios;

- Políticas públicas para o desenvolvimento de atividades econômicas, que consistem, principalmente, nos polos de competitividade e nos clusters, cujo objetivo é promover a cooperação em territórios escolhidos entre empresas e estabelecimentos de pesquisa e treinamento.

\section{O planejamento territorial no Brasil}

A estruturação do planejamento territorial no Brasil, se dá a partir do final da década de 50 , em grande medida, influenciado pela difusão de ideias oriundas da Comissão Econômica para a América Latina e o Caribe (CEPAL). No ano de 1956, é estruturado o Plano de Metas de Juscelino Kubitschek, que culmina com a construção de Brasília. Na mesma época, também com base no pensamento cepalino e, inspirado nas políticas americanas do New Deal, foi criado o Grupo de Trabalho para o Desenvolvimento do Nordeste (GTDN), que resultou em uma série de ações para a redução das desigualdades regionais, com ênfase no Nordeste.

As políticas de planejamento territorial no Brasil até os anos 1980

Até os anos 30, as ações relativas ao planejamento territorial estavam relacionadas à necessidade de consolidar as fronteiras, tanto no Período Imperial quanto na República Velha. A construção de núcleos de habitação nas regiões de fronteira e da infraestrutura estratégica de ferrovias e portos são indícios dessa estratégia. Nesse período, a economia brasileira seguiu o pensamento liberal no que tange ao seu desenvolvimento, fortemente influenciada pelo discurso conservador das oligarquias agrárias (RÜCKERT, 2001, p. 67).

A partir dos anos 1930, gradativamente, o contexto econômico passou a ser influenciado pelo pensamento keynesiano. Na América Latina, esse modelo foi difundido a partir da CEPAL e, no Brasil, assumiu traços populistas no chamado nacional-desenvolvimentismo. A partir de então, a ação estatal começa a aparecer de forma mais estruturada, tanto em ações para coordenar o processo de industrialização quanto no planejamento das infraestruturas. Do ponto de vista da organização do território começam a ser notadas ações setoriais, principalmente vinculadas à infraestrutura, como no caso do Plano Geral de Viação, proposto pela Constituição de 1934. 
Dos anos 30 aos anos 50 são elaborados os primeiros relatórios e planos sobre a economia brasileira, todos com forte componente economicista e setorial. São exemplos o chamado Niemeyer Report, elaborado pelo britânico Otto Niemeyer, a convite do Governo Brasileiro; a análises da chamada Missão Cooke, formada por técnicos americanos patrocinados pelos Governos Brasileiro e Americano, realizada entre reentre os anos de 1942 e 1945; e o Plano SALTE, elaborado no ano de 1947, durante o Governo Eurico Gaspar Dutra (BAER, 2002, p.62-63).

Nos anos 50, no Governo Getúlio Vargas, o Estado Nacional assumiu um papel de forte indução à industrialização, com a criação do Banco Nacional de Desenvolvimento (BNDE) e da Petróleo Brasileiro S.S. (PETROBRAS). Essa ação foi reforçada no Governo Juscelino Kubitschek, com o Plano de Metas, mesclando a ação do Estado com a abertura para o capital privado, tanto nacional quanto internacional.

Entre os anos de 1953 e 1955, a CEPAL e o BNDE também realizaram um grande esforço para o planejamento da economia brasileira que influenciou diretamente o planejamento futuro, especialmente a elaboração do Plano de Metas, no ano de 1956, durante o Governo Juscelino Kubitschek. Esse plano pode ser considerado como a primeira ação sistemática do Estado para o planejamento territorial, uma vez que integrava temas referentes à energia e ao transporte, à indústria e, destacadamente, propunha a construção de Brasília (BRASIL/MPOG, 2002, p.12).

O agravamento da situação de subdesenvolvimento do Nordeste brasileiro fez com que, no ano de 1956, fosse criado o Grupo de Trabalho para o Desenvolvimento do Nordeste (GTDN). O Grupo incorporava a Comissão de Investimentos do Nordeste, criada no então Ministério de Viação e Obras Públicas no ano de 1954 e, de suas iniciativas, resultou a criação da Superintendência do Desenvolvimento do Nordeste (SUDENE) no ano de 1959. A SUDENE atuou na implementação de um centro complementar ao Sudeste brasileiro, cuja proposta, de acordo com Furtado (1981, p.16), assentava-se na substituição de importações, na introdução de modificações estruturais no meio rural e em um grande esforço de transferência de recursos para a região visando à constituição de um polo de desenvolvimento complementar ao sudeste brasileiro.

A partir de 1964, o desenvolvimentismo brasileiro perdeu seu componente populista e passou a ter um caráter geopolítico e centralizador. No que tange ao planejamento territorial, destacam-se os Planos Nacionais de Desenvolvimento (PNDs), que passaram a vigorar a partir de 1972. O I PND, elaborado no governo do presidente Médici deu início à fase denominada de milagre brasileiro, com grande crescimento econômico e abertura ao capital externo. Do ponto de vista territorial, a estratégia organizava um grande esforço de integração nacional, preparando a infraestrutura para o crescimento. É desse período o planejamento e o início da construção da Transamazônica, da hidrelétrica Três Marias, da ponte Rio-Niterói e de Itaipu. 
O II PND, parcialmente implantado a partir de 1975, durante o governo Geisel, consolidou esse esforço, com ações relacionadas à infraestrutura, energia e, principalmente, com a forte presença intervencionista do Estado, que ficava evidente na criação de muitas empresas estatais. No período, foram gestados Proálcool, o programa de energia nuclear e fortalecida a ação da Petrobrás. O III PND, durante o governo Figueiredo, ignora o contexto de crise e mantém a meta de crescimento acelerado e, por óbvio não chega a ser executado.

O final da década de 80 é marcado pelo auge da crise do petróleo e marca o fim do desenvolvimentismo no Brasil. Da mesma forma, caracteriza o esvaziamento do planejamento e das políticas governamentais relacionadas ao território, tornando as iniciativas posteriores meramente formais. A partir desse momento, os esforços foram direcionados para outras temáticas como a redemocratização brasileira, a crise monetária, o combate à inflação, a questão da dívida externa e a busca de novas estratégias de desenvolvimento.

De forma geral, pode-se afirmar que, até o final da década de 80, o planejamento brasileiro apresenta um forte componente tecnocrático e estatal, fato que se repete em relação ao planejamento territorial. Esse se inicia com a preocupação com os desequilíbrios regionais e o subdesenvolvimento do Nordeste brasileiro e, posteriormente, ganha contornos estratégicos de ocupação do território e integração nacional, sendo executado por meio de planos desarticulados, principalmente voltado às infraestruturas estratégicas. Segundo Vainer (2007, p.11), esses chamados Grandes Projetos de Investimento geraram nexos entre o Sudeste e o resto do país, embora, ao mesmo tempo, tenham conformado verdadeiros enclaves territoriais, introduzindo um importante fator de fragmentação.

As políticas de planejamento territorial no Brasil após os anos 1980

A partir da Constituição Brasileira de 1988 foram instituídos e articulados os instrumentos que constituem o sistema de planejamento que vigora até os dias atuais, a saber: o Plano Plurianual (PPA) - médio prazo (quatro anos), a Lei do Orçamento Anual (LOA) - curto prazo e a Lei de Diretrizes Orçamentárias (LDO), que articula os dois primeiros.

Entretanto, foi a partir da estabilidade econômica, obtida em 1994 com o Plano Real, que foram criadas as condições para uma maior valorização do planejamento e, também, de seu viés territorial. Entretanto, mesmo após sua retomada, a história do planejamento territorial no Brasil caracteriza-se pela descontinuidade e, de certo modo, pela desarticulação, com estudos e iniciativas isoladas para elaborar políticas de desenvolvimento e ordenamento territorial, ou mesmo com tentativas de inserir o componente territorial em políticas setoriais. 
A elaboração do Programa Brasil em Ação4, em 1996 e Estudo dos Eixos Nacionais de Integração e Desenvolvimento $^{5}$, foram as primeiras iniciativas a trazer de volta a preocupação com o planejamento territorial, principalmente no que tange à articulação com os países vizinhos, em um contexto de globalização. O Estudo dos Eixos visava ao fortalecimento da base estratégica do Plano Plurianual 1996-1999 e tinha como objetivos a integração nacional e internacional, o aumento da competitividade sistêmica da economia e a redução das disparidades sociais e regionais. Esses estudos foram atualizados e ampliados em duas outras edições, que subsidiaram a elaboração dos Planos 2000-2003 e 2004-2007.

Outra iniciativa a ser destacada é a criação do programa de atenção às Regiões Diferenciadas, no ano de 1995. Esses estudos definiram recortes mais precisos para as políticas públicas de acordo com as desigualdades regionais brasileiras que, mais tarde, foram incorporadas como uma das escalas da PNDR (CARGNIN, 2012, p.20).

Também foi relevante para o reposicionamento do planejamento territorial a criação do Ministério da Integração Nacional (MI), no ano de 1999. Embora nunca tenha assumido lugar estratégico na agenda governamental, o MI teve papel relevante ao organizar algumas das principais políticas territoriais recentes levadas a diante no país, tais como a construção da Política Nacional de Desenvolvimento Regional (PNDR) e a tentativa de elaboração da Política Nacional de Ordenamento Territorial (PNOT), a partir do ano de 2003.

A PNDR prosperou, tendo sido formalizada pelo Decreto 6.047, de 22 de fevereiro de 2007, com posteriores tentativas frustradas de atualização e transformação do mesmo em Lei. Já a discussão da PNOT não chegou a bom termo, sendo que ano de 2006, foi apresentada uma proposta inicial e, a partir desse momento, as discussões foram interrompidas.

Do ponto de vista dos estudos que embasaram a manutenção do planejamento territorial na agenda governamental, destaca-se a elaboração do Estudo da Dimensão Territorial para o Planejamento, contratado pelo Ministério do Planejamento, Orçamento e Gestão, no ano de 2007. O objetivo central desse estudo foi subsidiar a dimensão territorial na elaboração do Plano Plurianual 2008-2010. Embora sua implementação tenha sido insignificante, uma vez que o PPA não incorporou nenhum dos resultados propostos, o estudo realizou uma reflexão qualificada sobre o planejamento territorial, recuperando uma ideia de estratégia nacional de desenvolvimento.

Além da PNDR outras políticas setoriais apresentaram ênfase territorial. Nesse sentido, ao apresentar o planejamento territorial no Brasil recente, Araújo (2012) organiza o desdobramento do mesmo em três

\footnotetext{
${ }^{4}$ O Programa Brasil em Ação foi lançado em agosto de 1996, priorizando 42 empreendimentos voltados para a promoção do desenvolvimento do País. A partir de 1999, o Brasil em Ação foi ampliado, incorporando outros 16 empreendimentos.

${ }^{5}$ O Estudo foi contratado em 1997 pelo Ministério do Planejamento Orçamento e Gestão, em parceria com o Banco Nacional de Desenvolvimento Econômico e Social (BNDES).
} 
categorias de políticas: um primeiro tipo de política, classificadas como políticas regionais explícitas, foram elaboradas com o propósito de atuar na redução das desigualdades regionais, à exemplo da PNDR; em um segundo grupo, estão as políticas setoriais que apresentam uma estratégia territorial, chamadas de implícitas, à exemplo do programa Territórios da Cidadania; já o terceiro grupo compreende as políticas destinadas a estimular as potencialidades regionais, como as direcionadas ao estímulo de arranjos produtivos.

Os dois primeiros grupos tratam da busca do equilíbrio territorial do processo de desenvolvimento, sendo objeto de preocupação maior do Estado. Apresentam dependência da capacidade do Estado em se antecipar ante aos problemas que se apresentam e, normalmente, estão associadas a fortes intervenções, sejam elas de financiamento público ou de programas setoriais para o fomento, ao desenvolvimento e à redução das desigualdades. O terceiro grupo, na maioria das vezes, está associado ao papel de organização dos atores para o desenvolvimento, tendo sido muito difundido a partir dos anos 80, apoiado nos clássicos exemplos da Terceira Itália e do Vale do Silício.

No Brasil, muitas são as tentativas de políticas que, por meio de uma estratégia setorial buscam promover o desenvolvimento e o equilíbrio territorial. O Programa Territórios da Cidadania foi lançado como uma estratégia regional e sustentável de desenvolvimento e de universalização dos programas destinados à inserção de públicos fragilizados nas áreas rurais ${ }^{6}$. Basicamente, atuava no sentido de integrar políticas setoriais nas diferentes esferas de governo, tendo como foco um conjunto de territórios selecionados. Apesar de um discurso territorial bem construído, o programa funcionava com a articulação de ações existentes nos diferentes órgãos, com pouca ou nenhuma articulação com a PNDR. Não é objetivo questionar a eficiência do Programa ou mesmo a qualidade de sua construção territorial, mas sim observar que o mesmo se mostra como um exemplo de desarticulação da política territorial com a ação setorial no Brasil, uma vez que se trata de uma construção paralela sobre o planejamento territorial.

O Programa Bolsa Família foi instituído no ano de 2003, como consolidação de um conjunto de ações estruturadas desde o início da década de 70, como instrumento para a redução da pobreza extrema no país. Trata de reconhecer que a pobreza se constitui em um problema estrutural e necessita de implementação de políticas públicas assistenciais para sua superação. Muitos são os estudos que abordam diferentes aspectos da sua implementação e de seus resultados entendidos como exitosos, embora a maior parte deles não se ocupe da reinserção ativa desses públicos. O fato é que o grande alcance do programa e seu efeito nas populações mais vulneráveis, especialmente nas regiões Norte e Nordeste brasileiro, têm mostrado que seus efeitos não se restringem a aspectos distributivos da renda, mas têm contribuído também para reduzir as desigualdades regionais (CARGNIN, BANDEIRA; 2015).

\footnotetext{
6 Materiais sobre o programa ainda estão disponíveis no site do Ministério do Desenvolvimento Agrário: http://www.mda.gov.br/sitemda/sites/sitemda/files/ceazinepdf/3638408.pdf
} 
O fato que não pode ser negligenciado é que, mesmo com esse aspecto evidente, o mesmo não apresenta articulação com a PNDR, o que, com pressupostos e especificidades distintas, se repete no caso do Programa Territórios da Cidadania. Mais do que isso, pode-se dizer que é a regra da construção setorial versus territorial no Brasil.

Em outra direção, para Vainer (2007), os chamados Grandes Projetos de Investimento que, atualmente, ao contrário do período desenvolvimentista, apresentam um caráter privado, o neo-localismo competitivo e empreendedorista, ligado a uma guerra de lugares por investimentos, e os velhos regionalismos e localismos, típicos do Estado brasileiro, são três vetores que operam para a fragmentação do território nacional. Esses aspectos contribuem para a não formação de uma agenda nacional para o desenvolvimento. Historicamente, como observamos, mesmo quando essa agenda esteve presente no Brasil, a questão regional ocupou apenas uma posição marginal.

\section{A articulação entre as políticas setoriais no Brasil e na França: a Política Nacional de Desenvolvimento} Regional (PNDR) e os Contratos de Plano Estado-Região (CPER)

Com a descentralização política na França e a atribuição de recursos aos conselhos regionais, um dos principais desafios da administração francesa passou a ser colocar em coerência as políticas públicas do governo central e das regiões. Para isso, foram criados, em 1984, os Contratos de Plano Estado-Região (CPER).

Os CPER possuem uma duração de 5 anos. Atualmente, está vigendo o contrato de plano 2015-2020, com investimentos previstos de 30 bilhões de euros em 5 anos, sendo 15 bilhões oriundos do Estado e 15 bilhões das regiões. Além dos CPER regionais, há contratos de plano para o massif francês e para os rios. A Figura 1 representa o conteúdo dos CPER 2015-2020: 
Figura 1. Os elementos dos CPER 2015-2020. Fonte: CGET (2018). Elaboração: autores

Elementos do CPER

\begin{tabular}{|c|c|c|c|c|}
\hline $\begin{array}{l}\text { Mobilidade } \\
\text { multimodal } \\
\\
\text { - Rodovias } \\
\text { - Ferrovias } \\
\text { - Portos } \\
\text { - Plataformas } \\
\text { multimodais }\end{array}$ & \begin{tabular}{l}
\multicolumn{1}{c}{ Ensino } \\
superior e \\
Pesquisa \\
\\
- Imóveis das \\
universidades \\
- Residência \\
estudantil \\
- Projetos de \\
pesquisa \\
- Divulgação \\
de pesquisas \\
para atores \\
econômicos
\end{tabular} & $\begin{array}{l}\text { Transição } \\
\text { Ecológica e } \\
\text { Energética } \\
\text { - Eficiência } \\
\text { energética } \\
\text { - Desenvolv. } \\
\text { de energias } \\
\text { reniováveis } \\
\text { - Economia } \\
\text { circular } \\
\text { - Prevenção de } \\
\text { riscos naturais } \\
\text { - Biodiversidade } \\
\text { - Educação }\end{array}$ & $\begin{array}{c}\begin{array}{c}\text { Transformação } \\
\text { Digital, } \\
\text { Inovação, } \\
\text { Usina do Futuro }\end{array} \\
\text { - Estratégia de } \\
\text { desenvolvimento } \\
\text { digital } \\
\text { - Plano da } \\
\text { França } \\
\text { - Áreas com alta } \\
\text { ocupação } \\
\text { - Zonas menos } \\
\text { ocupadas } \\
\text { - Programas de } \\
\text { investimento } \\
\text { futuro }\end{array}$ & $\begin{array}{l}\quad \text { Dimensão } \\
\text { Territorial } \\
\text { - Acompanhar os } \\
\text { projetos dos } \\
\text { territórios e das } \\
\text { coletividades } \\
\text { - Planejamento } \\
\text { urbano } \\
\text { - Acesso aos } \\
\text { serviços } \\
\text { públicos } \\
\text { - Territórios } \\
\text { rurais e perime- } \\
\text { tropolitanos } \\
\text { - Projetos } \\
\text { culturais }\end{array}$ \\
\hline
\end{tabular}

Os principais objetivos dos CPER são:

- colocar em coerência as intervenções ministeriais do Estado nos territórios;

- articular as políticas públicas nacionais e regionais;

- mobilizar investimentos do Estado para um período de 5 anos;

- garantir a coesão dos territórios;

- promover uma abordagem transversal das políticas públicas;

- articular as questões locais, regionais, nacionais e internacionais.

Segundo o Comissariat général à l'égalité des territoires (CGET, 2018), a elaboração e a negociação dos CPER consistem em 5 pontos principais:

1. Produção de caderno de encargos ministerial: Elaborado pelos ministérios e destinado aos prefeitos das regiões, retoma os objetivos dos ministérios. Passa por uma validação interministerial, com o apoio do CGET.

2. Realização de diagnósticos e estratégias regionais: Exercício coordenado pelos prefeitos das regiões e os Conselhos Regionais. Devem ter coerência com as políticas do Governo nacional e os fundos europeus de investimento. 
3. Elaboração de mandatos de negociação: Ocorre uma análise das estratégias regionais pelo CGET e pelos ministérios. Também há a definição pelos ministérios do orçamento disponível para cada CPER. Por fim, ocorre o envio, pelo Primeiro Ministro, dos mandatos de negociação os quais os prefeitos deverão respeitar.

4. Negociações regionais: Ocorrem negociações entre os prefeitos, os conselhos regionais e as outras coletividades. Também ocorre a organização das ações e a identificação das operações a financiar. É promovida uma consulta à população. Também se dá a arbitragem do Primeiro Ministro para questões orçamentárias complementares.

5. Validação nacional e regional: Dá-se uma avaliação ambiental dos CPER e a validação interministerial de cada CPER e de seus orçamentos. Ocorre a autorização do Primeiro Ministro ao Prefeito da Região para assinar o CPER junto ao Presidente do Conselho Regional.

É importante afirmar também que, a partir de 1975, com a criação do Fundo Europeu de Desenvolvimento Regional (FEDER), a França passou a se inserir na política regional da Europa. Nesse sentido, os CPER têm que apresentar coerência também com os objetivos estabelecidos em nível continental. A própria reforma das regiões, ocorrida entre os anos de 2013 e 2014, teve como objetivo adequar a regionalização francesa à da União Europeia.

Nesse sentido, os CPER permitem uma maior articulação entre as diferentes ações do governo central visando ao desenvolvimento das regiões francesas. No Brasil, a desagregação das ações setoriais e a fragmentação do território dificultam a articulação de políticas voltadas ao desenvolvimento regional. Uma das tentativas de agregar ações governamentais visando ao desenvolvimento de regiões se deu com a PNDR que teve suas primeiras ações no início dos anos 2000.

Pautada na superação das desigualdades regionais e fortemente influenciada pelo conceito de regiãoproblema, a elaboração da PNDR buscou estimular e apoiar a constituição de arranjos produtivos locais promissores nas diferentes regiões e melhor distribuir os investimentos públicos territorialmente. A partir de uma abordagem multiescalar, a PNDR utilizou recortes espaciais já existentes, como por exemplo o das grandes regiões brasileiras e das regiões diferenciadas, e construiu novas regiões de intervenção, pautadas por uma tipologia.

A tipologia serviu como referência para a identificação dos territórios priorizados, utilizando critérios de elegibilidade definidos pela combinação de dois indicadores básicos de renda e dinamismo, publicados pelo IBGE: o rendimento médio mensal por habitante e a taxa geométrica de variação dos produtos internos brutos municipais por habitante. 
Do ponto de vista metodológico, adotou como estratégia de ação a multiescalaridade, com quatro níveis escalares: o supranacional, o macrorregional e de regiões especiais, o sub-regional e o intraurbano. Já do ponto de vista instrumental, utilizou planos, programas e fundos, de acordo com as diferentes escalas. A escala macrorregional, foi pautada pela tradicional percepção das desigualdades regionais entre as grandes regiões brasileiras. Ganharam destaque os Planos Estratégicos de Desenvolvimento, em especial nos casos das Regiões Norte, Nordeste e Centro-Oeste. Depois de sua recriação, as Superintendências Regionais de Desenvolvimento da Amazônia (SUDAM), do Nordeste (SUDENE) e do Centro-Oeste (SUDECO) foram responsáveis pela elaboração e implementação de tais peças de planejamento.

A escala sub-regional utilizou e ampliou os recortes pré-existentes das Mesorregiões Diferenciadas, trabalhando também no nível das Regiões Integradas de Desenvolvimento (RIDEs), do Semi-Árido e da Faixa de Fronteira ${ }^{7}$. A partir dessa abordagem resultam, no Plano Plurianual, programas e ações específicos para cada uma das áreas prioritárias da PNDR.

De forma prioritária, para as Mesorregiões Diferenciadas e para o Semi-Árido, a PNDR organizou o Programa de Sustentabilidade de Espaços Sub-Regionais (PROMESO). Foram organizadas 13 Mesorregiões Diferenciadas e dez outras Microrregiões selecionadas ${ }^{8}$, que tiveram ações desenvolvidas até o final da vigência do Plano Plurianual 2008-2011, quando o programa foi encerrado.

Para a Faixa de Fronteira, a partir de um amplo estudo denominado de Proposta de Reestruturação do Programa de Desenvolvimento da Faixa de Fronteira ${ }^{9}$, foi elaborado o Programa de Desenvolvimento da Faixa de Fronteira (PDFF), com ações predominantemente nas cidades de fronteiras ou cidades gêmeas.

No Semi-Árido, as ações foram organizadas pelo Programa de Desenvolvimento Integrado e Sustentável do Semi-Árido (CONVIVER). Já para as RIDEs, foi elaborado o Programa de Desenvolvimento das Regiões Integradas, com a implantação de um novo modelo de gestão do território que tratava especialmente de áreas metropolitanas situadas em mais de um estado.

Os fundos foram instituídos a partir da Constituição de 1988, e com a PNDR passaram a ser instrumentos financeiros para investimentos do setor privado. Apresentam-se como fundos para financiamento do setor

\footnotetext{
7 Pelos critérios da PNDR, as RIDEs localizam-se nas grandes regiões Norte, Nordeste e Centro-Oeste do País e, quando da publicação da Política, já haviam sido definidas três RIDEs: a RIDE do Polo de Juazeiro e Petrolina, a Ride da Grande Teresina (Timon) e a RIDE do Entorno do DF. A Região da Fronteira, por sua vez, corresponde a uma faixa territorial de até cento e cinquenta quilômetros, ao longo das fronteiras terrestres.

8 O Decreto 6.047, de 22 de fevereiro de 2007, que instituiu a PNDR, estabelecia 13 Mesorregiões Diferenciadas: Alto Solimões, Bico do Papagaio, Chapada do Araripe, Chapada das Mangabeiras, Grande Fronteira do MERCOSUL, Bacia do Itabapoana, Metade Sul do Rio Grande do Sul, Seridó, Vales do Ribeira e Guaraqueaçaba, Vale do Rio do Acre, Vales do Jequetinhonha e do Mucuri, Xingó e Águas Emendadas. Também estabelece como regiões de interesse as sub-regiões de São Raimundo Nonato (PI), Médio e Baixo Jaguaribe (CE), Vale do Açu (RN), Souza - Piancó (PB), Sertão do Moxoxó (PE), Sergipana do São Francisco (SE), Brumado/Bom Jesus da Lapa/Guanambi (BA), Serra Geral (MG). Posteriormente, através do Decreto 6290 de 07 de dezembro de 2007, foi criada a SubRegião da Área de Abrangência do Plano da BR-163 Sustentável.

${ }^{9}$ BRASIL/MI (2005). O estudo está disponível junto ao site do Ministério da Integração Nacional <http://www.integracao.gov.br>.
} 
privado, constituindo-se em uma linha de crédito acessível. Os principais fundos existentes são os Fundos Constitucionais de Financiamento (FNE, FNO e FCO) e os Fundos de Desenvolvimento Regional do Nordeste e da Amazônia (FDNE e FDA) ${ }^{10}$.

No PPA 2008-2011, os programas que funcionavam como instrumentos financeiros principais para as ações do Estado foram encerrados, decretando o enfraquecimento da PNDR. Isso porque o principal instrumento proposto pela política, o Fundo Nacional de Desenvolvimento Regional (FNDR), aos moldes Fundo Europeu de Desenvolvimento Regional, nunca foi concretizado. Esse Fundo deveria ser capaz de financiar ações estratégicas para o desenvolvimento regional, não cobertas pelos fundos exclusivamente destinados ao financiamento de empresas.

Assim, com a ausência de um instrumento capaz de atuar profundamente sobre as desigualdades regionais brasileiras e com uma política regional que sequer apresenta meios de operacionalização no planejamento formal, o que se efetiva com o fim dos programas que sustentavam a PNDR, essa pode ser caracterizada como um esforço incompleto. A mobilização acadêmica e de gestores que acreditavam na PNDR como um instrumento de integração nacional e de redução das históricas desigualdades brasileiras não passou de um esforço, uma vez que seus instrumentos não foram criados e sua inscrição na agenda política é marginal.

Do ponto de vista da articulação com o planejamento governamental, a implantação de uma nova metodologia para a elaboração do Plano Plurianual 2012-2015, baseada em programas temáticos, significou o fim dos programas vigentes e, por consequência da PNDR nos moldes existentes. Os canais de articulação da Política com o planejamento formal, especialmente o Plano Plurianual, foram desestruturados e a nova forma de atuação tornou o tema ainda mais difuso, enfraquecendo a importância da temática na agenda federal.

Em 2012, visando rediscutir a PNDR, o Ministério da Integração Nacional (MI) organizou a Conferência Nacional de Desenvolvimento Regional (CNDR), centrada no tema Desenvolvimento Regional para Integração Nacional. O processo, realizado entre agosto de 2012 e março de 2013, envolveu Conferências estaduais e macrorregionais, culminando com um evento nacional denominado Semana do Desenvolvimento Regional. O objetivo central da Conferência foi elaborar princípios e diretrizes para a atualização da Política Nacional de Desenvolvimento Regional. Como resultado, foram aprovados 21 princípios e 95 diretrizes, incluídos em uma proposta de Projeto de Lei visando institucionalizar a PNDR como política de Estado. O Projeto foi enviado pelo MI à Casa Civil da Presidência e encaminhado ao Congresso Nacional, tendo desaparecido da pauta do Legislativo.

10 Os Fundos de Desenvolvimento do Nordeste e da Amazônia (FDNE e FDA) foram instituídos quando da criação das Agências de Desenvolvimento do Nordeste e da Amazônia (ADENE e ADA), no ano de 2001, e ainda não estão operando. (GALVÃO, 2007, p. 340). 
Em 2019, o tema retorna à agenda por meio do Decreto 9.810 de 30 de maio de 2019, que novamente institui a Política Nacional de Desenvolvimento Regional. A nova PNDR, não segue os princípios e diretrizes discutidas na CNDR, e modifica substancialmente o Decreto de 2006. São arrolados como princípios a solidariedade regional e cooperação federativa transparência e participação social; o planejamento integrado e transversalidade da política pública; a atuação multiescalar no território nacional; o desenvolvimento sustentável; o reconhecimento e valorização da diversidade ambiental, social, cultural e econômica das regiões; competitividade e equidade no desenvolvimento produtivo; e a sustentabilidade dos processos produtivos (BRASIL, 2019).

Dentre os princípios estão: a promoção da convergência de níveis de desenvolvimento e de qualidade entre as regiões, a consolidação de uma rede de cidades policêntrica como estratégia à desconcentração do desenvolvimento; o estímulo à produtividade e ao amento da competitividade regional; e o fomento a agregação de valor da produção e a diversificação das cadeias produtivas. (BRASIL, 2019).

A Estratégia de atuação está calcada na governança, com a instituição do Sistema de Governança do Desenvolvimento Regional, visando articular a ação governamental, tanto do ponto de vista setorial, quanto da cooperação federativa e da articulação regional. Além disso, pressupõe a criação do Núcleo de Inteligência Regional no âmbito do Ministério do Desenvolvimento Regional e das Superintendências do Desenvolvimento da Amazônia, do Nordeste e do Centro-Oeste, estas regiões declaradamente prioritárias para a PNDR. Pelo Decreto, a estratégia será operacionalizada por programas e ações federais, monitoradas e acompanhadas pela criação do Sistema Nacional de Informações do Desenvolvimento Regional. (BRASIL, 2019).

Em fase inicial de implementação, resta saber se a PNDR poderá se constituir como uma ação efetiva para a redução das desigualdades regionais no Brasil. A não criação de um fundo nacional para seu financiamento a marginalidade do ministério proponente, bem como as dificuldades para a operacionalização de políticas públicas em tempos de crise, são desafios permanentes para a agenda territorial.

\section{CONSIDERAÇÕES FINAIS}

No Brasil, a marginalidade da PNDR na ação governamental brasileira e sua sobreposição por outras políticas setoriais com ênfase territorial refletem as dificuldades de articulação entre as políticas em prol das regiões com menor desenvolvimento. A falta de centralidade da questão territorial como promotora de uma maior transversalidade das políticas públicas é agravada pelo economicismo, pelo enfoque setorial e por velhos regionalismos e localismos, típicos do Estado brasileiro. Estes aspectos, somados a uma as disputas entre os territórios por novos investimentos globais, atuam como vetores de fragmentação territorial, 
contribuindo para a ausência de uma agenda nacional de desenvolvimento. Isso se reflete na falta de instrumentos e de recursos que possam alavancar políticas voltadas ao equilíbrio territorial.

Essa característica contrasta com os instrumentos utilizados pelo Estado francês visando ao desenvolvimento de suas regiões, com a centralidade dos Contratos de Plano na agenda estatal. Entretanto, também na França a política territorial está sendo revista e questionada. As dificuldades do Estado em manter seus compromissos em um contexto de redução do gasto público, a emergência de novos atores e o protagonismo das regiões, tem colocado dúvidas sobre o futuro do planejamento territorial.

A natural pressão provocada por uma nova onda liberal com o enfraquecimento do Estado, a falência dos modelos centralizados e tecnocráticos e a emergência de novos atores que assumem um maior protagonismo no desenvolvimento, tendem a reposicionar o quadro do planejamento territorial. Nesse contexto conturbado, o fato concreto é que os desequilíbrios territoriais tem se agravado, tanto no Brasil quanto na França, aumentando com isso a pressão por novas políticas e instrumentos construídos sob os alicerces da complexidade do mundo no século XXI.

\section{REFERÊNCIAS}

ARAÚJO, Tania Bacelar de. Tendências e Perspectivas do Desenvolvimento Regional no Brasil. Porto Alegre. I Conferência Estadual de Desenvolvimento Regional. 2012. (Apresentação em Power Point).

ARRIGHI, Giovanni. O longo século XX: dinheiro, poder e as origens do nosso tempo. São Paulo: Editora da UNESP. 2009.

BAER, Werner. A economia brasileira. São Paulo, Nobel, 2a ed. 2002. 507p.

BENKO, Georges. A ciência regional. Oeiras, Celta Editora. 1999.

BRASIL. Decreto № 9.810, de 30 de maio de 2019. Institui a Política Nacional de Desenvolvimento Regional. Brasília, Casa Civíl. 2019. BRASIL. MINISTÉRIO DA INTEGRAÇÃO NACIONAL (MI). Política Nacional de Desenvolvimento Regional. Documentos de referência e Decreto 6.047. 2007.

BRASIL. MINISTÉRIO DO PLANEJAMENTO, ORÇAMENTO E GESTÃO (MPOG). O Desafio do Planejamento Territorial. Brasília, MPOG, 2002. $32 \mathrm{p}$.

BRASIL. MINISTÉRIO DO PLANEJAMENTO, ORÇAMENTO E GESTÃO (MPOG). Estudo da Dimensão Territorial do PPA - (Volumes I a VIII). Brasília, MPOG/CGEE, 2008. 159 p. Disponível em: http://bibspi.planejamento.gov.br/handle/iditem/404. Acessado em 12 de dezembro de 2018.

CARGNIN, Antonio Paulo. A dimensão territorial do planejamento governamental: políticas de desenvolvimento regional no Estado do Rio Grande do Sul. Brasília, Revista Inclusão Social, v. 6, n. 1, 2012. p.13-32.

CARGNIN, Antonio Paulo; BANDEIRA, Pedro Silveira. A Política Nacional de Desenvolvimento Regional e as portas de saída para os beneficiários do Bolsa Família. Rio de Janeiro, Revista GeoUerj, n. 27, 2015. p. 234-257.

COSTA, Wanderlei Messias da. O Estado e as políticas territoriais no Brasil. São Paulo, Edusp, Contexto, 2001. p.83.

Commissariat général à l'égalité des territoires (CGET). Regards sur lês territoires: population - conditions de vie - éducation emploi transfrontalier. Raport 2017. Paris, 2018. P. 154.

Commissariat général à l'égalité des territoires (CGET). Les Contrats de Plan Etat - Régions: rencontre avec une délégation brésilienne. Paris, 2018. (apresentação em Power point) 
DESJARDINS, Xavier. L’aménagement du territoire. Paris: Armand Colin. 2017.

FALUDI, Andreas. The Rise and the Fall fron Grace and European Spatial Planning. In: DASí, Joaquín Farinós (Org). Territorio $Y$ Estados: Elementos para la coordinación de las políticas de Ordenación del Territorio en el siglo XXI. Valência, 2018. pp. 431-464

FURTADO, Celso. Uma política de desenvolvimento para o Nordeste. Novos Estudos CEBRAP. São Paulo, v.1, 1981. p.12-19.

FURTADO, Celso. Nova concepção de federalismo. In: Celso Furtado: essencial. São Paulo: Penguin Classics Companhia das Letras. 2013. 1a edição.

GALVÃO, Antônio Carlos. Desenvolvimento regional e inovação como instrumentos fundamentais para o desenvolvimento brasileiro. Revista Parcerias, Brasília, MCT, no 20, 2005. p.516-619

GILPIN, Robert. A economia política das relações internacionais. Brasília: Editora da UNB. 2002.

GIRARDON, Jean. Politiques d'aménagement du territoire. Paris: Ellipses. 2010.

KENNEDY, Paul. The rise and fall of the great powers: economic change and military conflict from 1500 to 2000. Nova York: Vintage Books Edition. 1989.

MONOT, Alexandra. La France, un territoire aménagé. Paris: Bréal. 2018.

PIKETTY, Thomas. Le capital au XXIe siècle. Paris: Édition du Seuil. 2013.

RÜCKERT, Aldomar Arnaldo. Reforma do Estado e tendências de reestruturação territorial. Cenários contemporâneos no Rio Grande do Sul. (Tese de Doutorado) - FFLCH, Programa de Pós-Graduação em Geografia Humana, Universidade de São Paulo. São Paulo, 2001. p.662.

SANTAMARIA, Frédéric. Aménagement du territoire in France, its foundations, its mutations and its challenges. In: DASÍ, Joaquín Farinós. Territorio y estados: elementos para la coordinación de las políticas de ordenación del territorio en el siglo XXI. Valência: Tirant Humanidades. 2018.

SUBRA, P. Géopolitique locale: territoire, acteurs, conflits. Paris: Armand Colin. 2016.

VAINER, Carlos B. Planejamento territorial e projeto nacional: os desafios da fragmentação. Revista Brasileira de Estudos Urbanos e Regionais, v.9, n.1. Maio de 2007. 